\title{
Primary Papillary Adenocarcinoma of Urinary Bladder: A Case Report
}

\author{
Raisa Ghosh ${ }^{1}$, Srishtidhar Mangal ${ }^{2}$, Sukla Naskar ${ }^{3}$, Keya Basu $^{4}$ \\ 1) $2^{\text {nd }}$ Year Postgraduate Trainee;2)Associate Professor;3)Assisstant Professor;4)Professor \& Head Of The \\ Department \\ Department Of Pathology,Calcutta National Medical College \& Hospital,Kolkata
}

\begin{abstract}
A 50 year old male presented with painless haematuria and nocturia since 3 months.Routine examination revealed mild anaemia and raised ESR.Ultrasonography of Kidneys,Bladder and Prostate showed an irregular mass in urinary bladder.An abdominal contrast enhanced computed tomography scan showed a $4 \mathrm{~cm}$ mass in the posterior wall of urinary bladder.Cystoscopy and Transurethral resection of the mass was done.Histopathology revealed it as Adenocarcinoma with muscle invasion.Surgical intervention in the form of cysto-prostatectomy, bilateral pelvic lymph node dissection, bilateral uretero-sigmoidostomy was done.A soft nodular exophytic growth was found in the posterior wall of urinary bladder.Histopathology and Immunohistochemistry confirmed it as Primary Papillary Adenocarcinoma.All other visceral sites were adequately excluded for primary adenocarcinoma.We are reporting this case as Primary papillary adenocarcinoma of urinary bladder, which is a rare neoplasm.
\end{abstract}

Keywords: Primary Papillary Adenocarcinoma, Urinary Bladder,Rare Neoplasm

\section{Introduction}

Primary adenocarcinoma of bladder is rare with an incidence of $0.5-2 \%$ of all bladder carcinomas. ${ }^{1,6}$ It may be of urachal in origin,associated with schistosomiasis or unassociated with any of these. ${ }^{1,2,6}$ Median age of presentation is around 50years with a slight male predominance.Prognosis in urachal ones is better than the nonurachal ones ${ }^{5}$ The 5 year survival rate is around $18-47 \%{ }^{1}$

\section{Case Report}

A male ,50years old,presented with painless haematuria and nocturia for past 3 months.His past medical history was unremarkable.Digital rectal examination excluded any evidence of prostatic or rectal malignancy.

\section{Investigations}

Transabdominal ultrasound showed a hypoechoic lesion in the urinary bladder.CECT of KUB region showed a lobulated ,predominantly solid mass in the posterior wall of urinary bladder;the mass had scatterred low attenuation areas.Cystoscopy and TURBT was done next;histopathology of the resected tumor confirmed it to be 'Moderately differentiated Adenocarcinoma of urinary bladder invading deeper muscle layer'.

\section{Surgery}

Following the above investigations,radical cystoprostatectomy,B/L pelvic lymph node dissection, $\mathrm{B} / \mathrm{L}$ ureterosigmoidostomy was done.

\section{Histopathology}

Grossly,a $4 \mathrm{~cm} \times 3.5 \mathrm{~cm} \times 2 \mathrm{~cm}$ exophytic,nodular mass was found to involve the posterior wall of urinary bladder;cut surface of the mass was yellowish white with minute foci of haemorrhage and necrosis.

Histopathology of the mass confirmed the diagnosis as Primary papillary adenocarcinoma of urinary bladder showing predominantly papillary architecture;papillae and variable sized glands are lined by malignant cells with abundant pale eosinophilic cytoplasm,marked nuclear pleomorphism and were found to dissect through muscularis propria.

Histopathology of the resected prostate showed Benign hyperplasia of prostate which excluded direct invasion of the bladder by prostatic adenocarcinoma. 


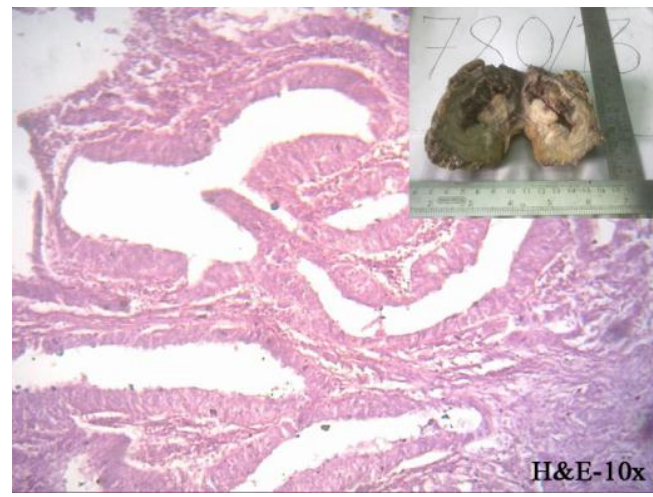

\section{Immunohistochemistry}

The neoplastic cells showed CK7 Positivity (thus excluding possibility of metastatic adenocarcinoma) and CK20 Negativity.

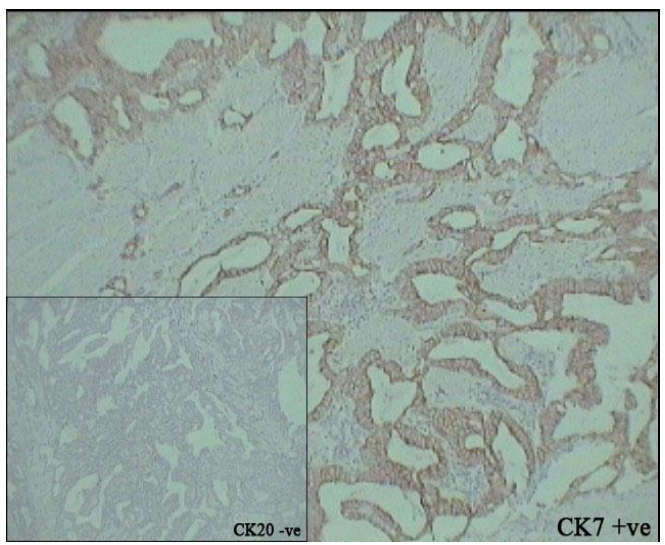

\section{Discussion}

Bladder adenocarcinomas are of three types- Primary,Urachal,Metastatic. ${ }^{6}$ Regarding histogenesis of Primary Adenocarcinoma of Urinary Bladder,Mostofi proposed that metaplastic changes consequent to chronic vesical irritation and infection may be the predisposing factor. ${ }^{1,3,4}$

Haematuria is the most common presenting symptom;other symptoms like mucosuria(rarely), dysuria,nocturia,frequency, pain may be present ${ }^{1,3,4}$

Histologic variations ${ }^{1,4}$ are- Adenocarcinoma NOS

Adenocarcinoma,enteric type

Adenocarcinoma with signet ring cells

Mucinous Adenocarcinoma

Clear cell Adenocarcinoma

Hepatoid Adenocarcinoma

Mixed Adenocarcinoma

Immunohistochemically,vesical adenocarcinomaas express CEA,CDX2,MUC1,MUC2,MUC3,same as colonic adenocarcinoma. ${ }^{1,2,3,4}$ CK7 and CK20 are usually positive unlike colonic adenocarcinoma. ${ }^{3,4,5}$

\section{Differential Diagnosis}

Local/metastatic spread

TCC with glandular differentiation

Intestinal metaplasia

Villous adenoma

Endometriosis,Endocervicosis,Endosalpingosis

\section{Conclusion}

Primary adenocarcinoma of urinary bladder is a rare neoplasm whreas metastatic adenocarcinoma is a comparitiively common entity.However,metastasis can be excluded clinically,radiologically and immunohistochemically. 


\section{References}

[1]. Christopher D.M Fletcher.Diagnostic Histopathology of tumors. $3^{\text {rd }}$ edition.Churchill Livingstone,Elsevier;2007.

[2]. Juan Rosai.Rosai and Ackerman's Surgical Pathology.10 $0^{\text {th }}$ edition.Mosby,Elsevier;2011

[3]. Stacey E.Mills.Sternberg's Diagnostic Surgical Pathology. $5^{\text {th }}$ edition.Wolter's Kluwer,Lippincot Williams \& Wilkins;2010.

[4]. Konstantinos Sigalas,Stavros I Tyritzis,Eleni Trigka,Ioannnis Katafigiotis,Nikolaos Kavantzas,Konstantinos G Stravodimos.A male presenting with a primary mucinous bladder carcinoma:A case report.Cases Journal.2010;3:49.

[5]. Mardi K,Gupta N.Urachal papillary cystadenocarcinomas:A rare case report.J Can Res Ther 2011;7:223-5. 